\title{
Harnessing plant reproduction for crop improvement: an introduction to the special issue
}

\author{
Thomas Dresselhaus • Emidio Albertini
}

Published online: 26 July 2013

(c) Springer-Verlag Berlin Heidelberg 2013

The European Plant Reproduction Network (Harnessing Plant Reproduction for Crop Improvement (HAPRECI)) was established in 2009 with financial support through the COST Action program of the European Commission. Its major goal was to stimulate research on plant reproduction in Europe and to combine interrelated and multidisciplinary expertise of the various laboratories. Scientific goals aimed to understand the molecular mechanisms of sexual and apomictic plant reproduction, and to facilitate the use of this knowledge in the development of new approaches in biotechnology, agriculture, and food industry through improved crops. Further goals aimed to promote interaction between fundamental and applied research areas, and to train young researchers in various methods and disciplines. Eighty-seven laboratories from 28 countries participated in the network.

After four successful years, the action will finish in October 2013 with a final network meeting in Oslo. In addition to annual meetings at Brussels (2009), Bristol (2010), Valencia (2011), and Porto (2012), a number of smaller focused workshops and summer training schools were organized. These included a Hypericum workshop in Austria, five $\mathrm{PhD}$ schools on plant reproduction associated with flower and vegetative development, plant breeding, and apomixis, respectively, which took place in Germany,

T. Dresselhaus $(\square)$

Cell Biology and Plant Biochemistry, Biochemie-Zentrum

Regensburg, University of Regensburg, Universitätsstraße 31,

93053 Regensburg, Germany

e-mail: thomas.dresselhaus@ur.de

E. Albertini $(\square)$

Department of Applied Biology, University of Perugia,

06121 Perugia, Italy

e-mail: emidio.albertini@unipg.it the Netherlands, Belgium, and Italy as well as a training school on metabolomics and plant breeding that was organized in Italy this year. The aim of the schools was to train young investigators in state-of-the-art methodologies employed for understanding plant reproduction and to improve crops. Therefore, additionally, a number of shortterm scientific missions (STSMs) were facilitated to exchange $\mathrm{PhD}$ students and young postdocs among partner laboratories for the purposes of training, collaborative research, and to promote innovative interactions.

The HAPRECI network was subdivided into three working groups with a focus on female gametophyte development and embryogenesis (WG1), male gametophyte development and pollen viability (WG2) as well as apomixis technology development (WG3). This special issue aims to indicate part of the activities and scientific achievements of the network. Each working group is represented by a review and a few original articles. The individual articles show scientific achievements, collaborations among the various European partners as well as the strong correlation between the various research topics.

WG1 worked on female aspects of plant reproduction and embryogenesis including the molecular characterization of meiosis, the analysis of genes expressed during gametogenesis, establishment of polarity, and cell specification as well as embryo patterning and the maternal control of embryo and seed development. Meiosis represents a key process during the initial stages of sexual plant reproduction culminating in the formation of gametes. In their review about the control of the meiotic cell division program in plants, Wijnker and Schnittger (2013) summarize the increasing knowledge on the major meiotic cell cycle players in plants. Moreover, they report that meiotic cell cycle checkpoints in plants are more relaxed compared with animals and thus allows modifications of the meiotic 
program to develop new plant breeding strategies. The detailed analysis of the meiosis gene $S G O 1$ in Arabidopsis (Zamariola et al. 2013) shows that this gene is necessary for the maintenance of centromere cohesion in meiosis I as disruption of AtSGO1 provokes precocious separation of sister chromatids before the onset of telophase I. At the same time, authors show that AtSGO2 is dispensable for both meiotic and mitotic cell progression in Arabidopsis. Part of this work was supported by an STSM grant. A further report describes the PMEII gene encoding a pectin methylesterase (PME) inhibitor that was identified in a screen for germline-specific genes from maize egg cells. Woriedh et al. (2013) could show that pollen tube burst is induced in vitro by the application of the recombinant protein to growing pollen tubes suggesting that it might act in concert with other proteins to release sperm cells during pollen tube perception.

These reports demonstrate the close interaction between WG1 and WG2, with the latter studying male gametophytic development and function as well as pollen viability. Future aims are to use the knowledge generated to produce, for example, male sterile plants or pollen lacking allergens, to overcome hybridization barriers, to modulate recombination and heterozygosity, and to produce doubled haploid plants during microspore embryogenesis. A pollen-specific $P M E$ gene was identified by Gomez et al. (2013) in pea. The authors studied its expression and pattern and could show that its promoter is active until the pollen tube releases the sperm cells inside the ovule. A number of articles in the special issue deal with microspore embryogenesis, which is widely used in plant breeding. An introduction to the topic is provided by Soriano et al. (2013). The authors summarize major concepts on microspore embryogenesis and compare data obtained from the study of zygotic and microspore embryo development. The dynamics and correlation of various genes expressed during pollen development as well as zygotic and microspore embryogenesis is reported by El-Tantawy et al. (2013) and Sanchez-Diaz et al. (2013). Arabinogalactan proteins (AGPs), highly glycosylated hydroxyproline-rich proteins, were studied in the first report. Using a multidisciplinary approach including immunolocalization, the authors analyzed the presence and localization of various AGPs during the reproductive stages mentioned above. In the second report, 14 genes were identified, which are induced during microspore embryogenesis in wheat. Comparison of gene expression pattern between zygotic and microspore embryogenesis revealed that the majority of genes displayed highest expression in zygotic embryos 12 days after pollination. One of the genes encoding a TPD1-like signalling peptide was also identified in wheat by Leljak-Levanić et al. (2013). This report deals with the identification of genes specifically induced in zygotes and proembryos as they may encode essential factors for these developmental stages. Original data of this paper support the hypothesis that the zygotic genome is activated shortly after fertilization and before the first zygotic division. In fact, authors were able to identify proembryo-expressed genes that were switched on already at the zygote stage. A popular energy crop that is only vegetatively propagated is Miscanthus $\times$ giganteus. Zur et al. (2013) investigated whether it is possible to induce microspore embryogenesis in this species in order to generate doubled haploids and thus to increase the biodiversity of this species. They showed that this approach is possible, but the low efficiency and the lack of regeneration ability currently prevent the broad application of this technique.

Finally, WG3 worked on apomixis (asexual reproduction through seeds) to understand the distribution and the spread of apomictic species, and to identify genes controlling the apomixis trait in these species with the ultimate goal to transfer the trait to crops. A review by Barcaccia and Albertini (2013) reports the main approaches that have been followed to isolate genes that prime the expression of apomixis in natural apomicts and/or the identification of genes that mime the features of apomictic pathways when they are deregulated in model sexual systems. Moreover, the link between apomixis and gene-specific silencing mechanisms is discussed. In particular, as microRNAs (miRNAs) have recently emerged as important regulators of posttranscriptional gene silencing involved in the development of embryo sacs, embryos, and seeds in plants, Galla et al. (2013) characterized mature miRNAs along with their precursors and potential targets in St. John's wort (Hypericum perforatum L.) to generate a comprehensive list of conserved miRNA families and to investigate the regulatory role of selected miRNAs in biological processes that occur in the flower. Overall findings pave the way toward discovering flower-specific miRNAs and predicting target genes that may differentiate and/or regulate the sexual and apomictic reproductive pathways. Also in this case, part of the work reported was carried out in partners' laboratories, thanks to STSM grants.

We hope you enjoy reading this special issue, and we would like to thank all authors who have send contribution and acknowledge our reviewers for their critical evaluation of the various manuscripts.

\section{References}

Barcaccia G, Albertini E (2013) Apomixis in plant reproduction: a novel perspective on an old dilemma. Plant Reprod. doi:10.1007/ s00497-013-0222-y

El-Tantawy AA, Solis MT, Da Costa ML, Coimbra S, Risueno MC, Testillano PS (2013) Arabinogalactan protein profiles and 
distribution patterns during microspore embryogenesis and pollen development in Brassica napus. Plant Reprod. doi:10. 1007/s00497-013-0217-8

Galla G, Volpato M, Sharbel TF, Barcaccia G (2013) Computational identification of conserved microRNAs and their putative targets in the Hypericum perforatum L. flower transcriptome. Plant Reprod. doi:10.1007/s00497-013-0227-6

Gomez MD, Renau-Morata B, Roque E, Polaina J, Beltran JP, Canas LA (2013) PsPMEP, a pollen-specific pectin methylesterase of pea (Pisum sativum L.). Plant Reprod. doi:10.1007/s00497-013-0220-0

Leljak-Levanić D, Juranić M, Sprunck S (2013) De novo zygotic transcription in wheat (Triticum aestivum L.) includes genes encoding small putative secreted peptides and proteins involved in proteasomal degradation. Plant Reprod. doi:10.1007/s00497013-0229-4

Sanchez-Diaz RA, Castillo AM, Valles MP (2013) Microspore embryogenesis in wheat: new marker genes for early, middle and late stages of embryo development. Plant Reprod. doi:10.1007/ s00497-013-0225-8
Soriano M, Li H, Boutilier K (2013) Microspore embryogenesis: establishment of embryo identity and pattern in culture. Plant Reprod. doi:10.1007/s00497-013-0226-7

Wijnker E, Schnittger A (2013) Control of the meiotic cell division program in plants. Plant Reprod. doi:10.1007/s00497-013-0223-x

Woriedh M, Wolf S, Marton ML, Hinze A, Gahrtz M, Becker D, Dresselhaus T (2013) External application of gametophytespecific ZmPMEI1 induces pollen tube burst in maize. Plant Reprod. doi:10.1007/s00497-013-0221-z

Zamariola L, De Storme N, Tiang CL, Armstrong SJ, Franklin FCH, Geelen D (2013) SGO1 but not SGO2 is required for maintenance of centromere cohesion in Arabidopsis thaliana meiosis. Plant Reprod. doi:10.1007/s00497-013-0231-x

Zur I, Dubas E, Slomka A, Dubert F, Kuta E, Plazek A (2013) Failure of androgenesis in Miscanthus $x$ giganteus in vitro culture of cytologically unbalanced microspores. Plant Reprod. doi:10. 1007/s00497-013-0219-6 